\title{
АНАЛИЗ СЛОЖНЫХ СМЕСЕЙ АРОМАТИЧЕСКИХ УГЛЕВОДОРОДОВ ХРОМАТОГРАФИЧЕСКИМИ МЕТОДАМИ
}

Ароматические углеводороды - главные компоненты смол высокотемпературной переработки горючих ископаемых, имеются они также в значительных количествах в жидких продуктах низкотемпературной деструкции, гидрогенизации и ожижения. В микроколичествах ароматические углеводороды обнаружены в выхлопных газах двигателей внутреннего сгорания, в сигаретном дыме, в копченых и жареных продуктах питания, в почве и воздухе.

Один из простейших методов определения состава полициклических ароматических углеводородов (ПАУ) - тонкослойная хроматография (TCX). При этом адсорбционном методе соединения разделяются в зависимости от их полярности - отношения $\mathrm{H} / \mathrm{C}$ и количества циклов в ПАУ. При применении ТСХ возможно идентифицировать до 10 соединений (качественный-полуколичественный анализ), а при препаративном разделении (количественный анализ) соединения разделяются только на отдельные группы близкой структуры. Наиболее надежный метод для определения индивидуального состава сложных смесей летучих соединений - газожидкостная хроматография (ГЖХ). При ГЖХ соединения разделяются в зависимости от их температуры кипения и полярности (на полярных фазах). При анализе прикладных смесей ароматических соединений анализ усложняется вследствие сложного изомерного состава и высокой температуры кипения соединений.

Цель настоящей работы - разработка комбинированной методики для анализа ПАУ, сочетающей ТСХ и ГЖХ. Соединения разделяются в зависимости от их полярности на структурные группы (ТCX), состав которых определяется методом ГЖХ на неполярных фазах. На указанных фазах соединения одной группы разделяются в зависимости от температуры кипения. Подобные методики уже разработаны нами для анализа смол полукоксования топлив [ $\left.{ }^{1}\right]$ и фенолов $\left[{ }^{2}\right]$.

Литературные данные по разделению ПАУ с помощью ТСХ можно сгруппировать в два направления. 1) Для разделения ароматики с числом колец до пяти адсорбентом служит силикагель или окись алюминия; элюируют малополярными растворителями, такими, как гексан [ $\left.{ }^{3}\right]$ или гексан с 5-10\%-ным содержанием хлороформа или эфира [4-7]; более полярные растворители применяют редко [4,8]. 2) Для разделения ПАУ с числом колец пять и более, а также для отделения их изомеров применяют сильнополярные смешанные растворители, состоящие из низших спиртов, ацетона, эфира, воды в разных пропорциях, адсорбент - ацетилированная целлюлоза [7,9-11]. Для улучшения разделения ПАУ иногда используют двукратное элюирование пластинки, 
Таблица 1

$\boldsymbol{R}_{f}$ полициклических ароматических углеводородов на пластинках «силуфол»

\begin{tabular}{|c|c|c|c|c|c|c|}
\hline \multirow[b]{2}{*}{ Соединения } & \multicolumn{6}{|c|}{ Элюент, \% об. } \\
\hline & 胥 & 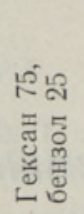 & 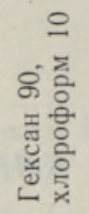 & 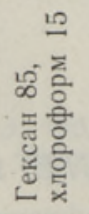 & 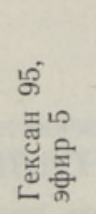 & 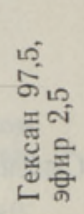 \\
\hline $\begin{array}{l}\text { Нафтален } \\
\text { Дифенилметан } \\
\text { Винилнафтален }\end{array}$ & $\begin{array}{l}57 \\
52 \\
51\end{array}$ & 84 & & 83 & $\begin{array}{l}\text { фронт } \\
\text { фронт }\end{array}$ & \\
\hline $\begin{array}{l}\text { Антрацен } \\
\text { Флуорен } \\
1,2 \text {-Бензантрацен }\end{array}$ & $\begin{array}{l}37 \\
35 \\
23\end{array}$ & 76 & 55 & $\begin{array}{l}59 \\
58 \\
46\end{array}$ & $\begin{array}{l}\text { фронт } \\
\text { фронт }\end{array}$ & $\begin{array}{l}65 \\
52\end{array}$ \\
\hline $\begin{array}{l}\text { 7,12-Диметилбензантрацен } \\
\text { Хризен } \\
1,2-5,6-\text { Дибензантрацен }\end{array}$ & $\begin{array}{l}21 \\
20 \\
13\end{array}$ & 61 & 41 & $\begin{array}{l}47 \\
45 \\
33\end{array}$ & $\begin{array}{l}69 \\
61\end{array}$ & $\begin{array}{l}51 \\
45 \\
38\end{array}$ \\
\hline $\begin{array}{l}\text { 1,2-Бензпирен } \\
20 \text {-Метилхолантрен }\end{array}$ & 15 & 57 & $\begin{array}{l}39 \\
38\end{array}$ & & 56 & \\
\hline
\end{tabular}

Таблица 2

$\boldsymbol{R}_{f}$ полициклических ароматических углеводородов на пластинках с незакрепленным слоем адсорбента

\begin{tabular}{|c|c|c|c|c|c|c|c|}
\hline \multirow[t]{2}{*}{ Наименование соединения } & \multirow{2}{*}{$\begin{array}{l}\begin{array}{l}\text { Элюент: } \\
\text { (\% об.) }\end{array} \\
\begin{array}{c}\text { Адсор- } \\
\text { бент: }\end{array}\end{array}$} & \multirow{2}{*}{$\frac{\text { Гексан }}{\mathrm{SiO}_{2}}$} & \multirow{2}{*}{\begin{tabular}{|c} 
Гексан \\
90, хло- \\
роформ \\
10
\end{tabular}} & \multicolumn{2}{|c|}{$\begin{array}{c}\text { Гексан } 85 \text {, } \\
\text { хлоро- } \\
\text { форм } 15\end{array}$} & \multicolumn{2}{|c|}{$\begin{array}{c}\text { Гексан } 97,5 \\
\text { эфир } 2,5\end{array}$} \\
\hline & & & & $\mathrm{SiO}_{2}$ & $\mathrm{Al}_{2} \mathrm{O}_{3}$ & $\mathrm{SiO}_{2}$ & $\mathrm{Al}_{2} \mathrm{O}_{3}$ \\
\hline
\end{tabular}

Антрацен

Хризен

1,2-Бензантрацен

7,12-Диметилбензантрацен

1,2-Бензпирен

20-Метилхолантрен

1,2-5,6-Дибензантрацен

Коронен

$\begin{array}{rr}25 & 29 \\ 18 & 12 \\ 16 & \\ 16 & \\ 14 & 10 \\ 12 & \\ 8 & \end{array}$

$29 \quad 28$

12

28

44

$30 \quad 52$

.

10

18

0 .

Для выбора подходящей системы растворителей и адсорбента было определено относительное расстояние пробега $\left(R_{f}\right)$ индивидуальных ПАУ на ТСХ-пластинках «силуфол» с закрепленным слоем адсорбента, а также на пластинках с незакрепленным слоем. Пластинки «силуфол» (Хемапол, Чехословакия) имели размер $15 \times 15$ cм, толщина слоя $0,2 \mathrm{Mм}$; хроматографирование проводили восходящим элюентом; пятна веществ обнаруживались по флуоресценции в ультрафиолетовом свете. Ряд величин $R_{f}$, полученных на пластинках «силуфол», приведен в табл. 1.

Так как сорбционные свойства «силуфола» и сорбентов, применяемых для препаративной ТСХ, значительно отличаются, окончательный выбор подходящего сорбента и системы растворителей проводили на пластинках $24 \times 24 \mathrm{~cm}$, с незакрепленным слоем, толщина слоя 0,8 м.м. Аналогично препаративному разделению элюирование проводилось нисходящим способом. Адсорбенты: силикагель L 100/160 (Хемапол, Чехословакия) и окись алюминия, нейтральная, активность по Брок- 
ману II (Венгрия). Основной задачей был выбор системы, где соединения с разным числом конденсированных ароматических циклов располагались бы на возможно большем расстоянии друг от друга, а общее среднее расположение было бы приблизительно в середине пластинки. Ряд данных $R_{f}$ эталонных веществ на пластинках с незакрепленным слоем адсорбента приведен в табл. 2. Удовлетворительные результаты достигнуты с элюентом гексан-хлороформ $(85: 15)$ и гексан-эфир $(97,5: 2,5)$ на окиси алюминия. Заместители конденсированного ядра, в том числе и по-иному расположенное дополнительное бензольное кольцо, по-разному влияют на величину $R_{f}$ на окиси алюминия и на силикагеле с тем же элюентом.

Для определения состава фракций ТСX, содержащих много компонентов, применяется ГЖХ. Сложные смеси хорошо разделяются при применении капиллярной хроматографии, эффективным методом анализа является сочетание ГЖХ с масс-спектрометрией (МС). В капилляре длиной $100 \boldsymbol{M}$ на апьезоне $L$ разделены ПАУ - алкилнафталины и метилбифенилы $\mathrm{C}_{12}$ каменноугольной смолы $\left[{ }^{12}\right]$, на полифениловом эфире - соединения до антрацена, выделенные из смолы высокотемпературного пиролиза $\left[{ }^{13}\right]$. На насадочных колонках $(3-6 \%$ дексила 300 на хромосорбе $W$ ) разделены серусодержащие ПАУ газовой сажи $\left[{ }^{14}\right]$, соединения до пирена - в табачном дыме [15] и до коронена - в пробах воздуха $\left[{ }^{16,17}\right]$. В последних работах $\left[{ }^{14-17}\right]$ использовалась капиллярная ГЖХ-MC. В качестве жидкой фазы берется и OV-101 - при анализе каменноугольной смолы в 18 -метровом капилляре $\left[{ }^{18}\right]$ и при анализе смазочных масел в 10-метровой стеклянной колонке [19]. Более новой фазой для разделения ПАУ является поли-S-179 [20].

В настоящей работе индивидуальный состав выделенных фракций и групп исследовался на хроматографе Хром-41 с пламенно-ионизационным детектором в условиях программирования температуры (скорость подъема температуры $2{ }^{\circ} \mathrm{C} /$ мин). Применялась 40 -метровая капиллярная колонка (внутренний диаметр 0,25 мм). Неподвижная фаза - дексил 300. Качественная расшифровка хроматограмм осуществлялась путем добавки к исследуемой смеси индивидуальных соединений, а также по индексам удержания, приведенным в литературе.

Эффективность разделения способом ТСХ проверялась при анализе ароматических углеводородов, выделенных из смолы камерных печей (продукт высокотемпературной переработки горючего сланца-кукерсита). Смола $\left(d_{4}^{20}=1,037, n_{D}^{20}=1,599\right)$ перед анализом была обесфенолена.

Для выделения ПАУ 0,5 г смолы подвергали разделению по [']. Использовались пластинки $24 \times 24 \mathrm{~cm}$, адсорбент - силикагель, толщина слоя - 2 мм, элюент - н-гексан. Распределение смолы на пластинке на группы представлено на рис. 1 (I - высокополярные соединения, остающиеся на стартовой линии, II - кислородные соединения, III - ПАУ, IV - алкилбензолы, V - парафины и олефины).

Хроматограммы ПАУ и алкилбензолов, полученные методом ГЖХ, изображены на рис. 2. Алкилбензолы, большинство которых имеет длинные $н$-алкильные боковые цепи, прннадлежат к нескольким гомологическим рядам. Они хорошо отделены от ПАУ. В составе последних много нафталина и метилнафталинов, которые частично проникают также в соседнюю полосу.

Выделенная фракция ПАУ подвергалась повторному разделению как на силикагеле, так и на окиси алюминия. Условия хроматографирования те же, что и при первом разделении, элюент - гексан-хлороформ $(85: 15)$, количество разделяемого вещества - 150 ма. Установлено, что 
CMO^A

Cunukarenb

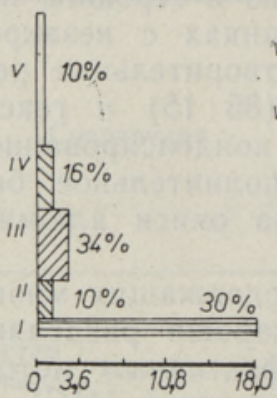

ПОАИЦИКАИЧЕСКАЯ АРОМАТИКА

Cunukazens

Okucb avamuнus
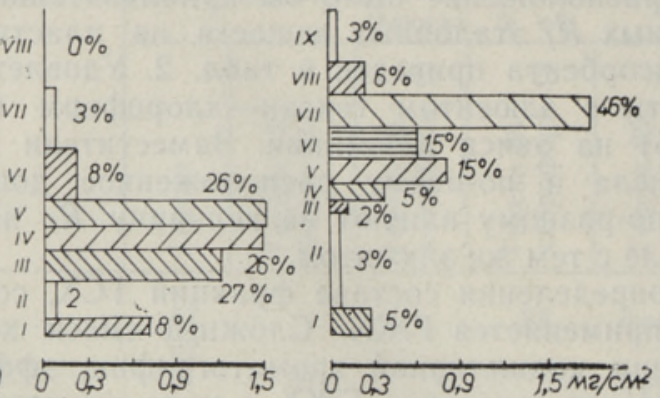

Рис. 1. Материальные балансы разделения в тонком слое смолы и ее фракции полициклических аорматических углеводородов.
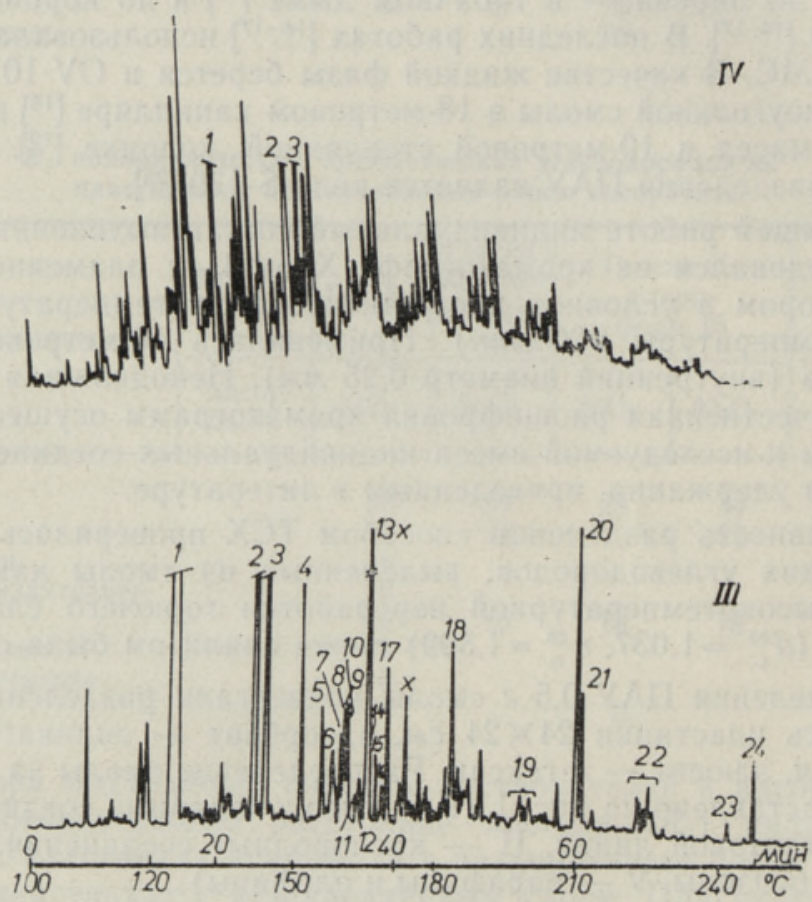

Рис. 2. Хроматограммы разделенных в тонком слое фракций смолы: III - полициклические ароматические углеводороды, IV - алкилбензолы. 1 - нафталин, 2 - 2-метилнафталин, 3 - 1-метилнафталин, 4 дифенил, 5 - 2-этилнафталин, $6-2,6$ - и 2,7-диметилнафталины, 7 1,7 -диметилнафталин, 8 - 1,3-диметилнафталин, $9-1,6$-диметилнафталин, $10-2$-метилдифенил, $11-2,3$-диметилнафталин, $12-1,4$ - и 1,5диметилнафталин, 13 - 4-метилдифенил, $14-1,2$-диметилнафталин, 15 - 3-метилдифенил, 16 - 1,8-диметилнафталин, 17 - аценафтен, 18 флуорен, 19 - метилфлуорены, 20 - фенантрен, 21 - антрацен, 22 метилфенантрены и метилантрацены, 23 - флуорантен, 24 - пирен, $\mathrm{x}$ - неидентифицированные сернистые соединения. 

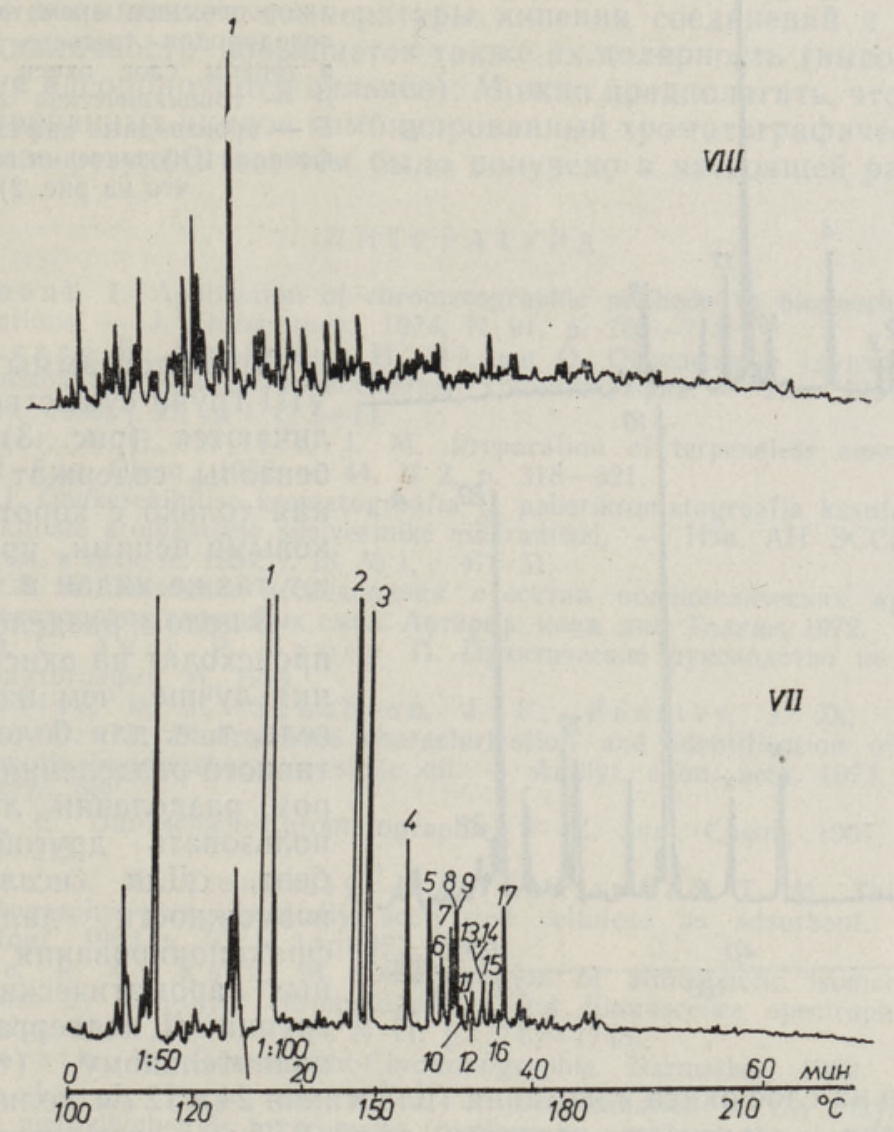

Рис. 3. Хроматограммы групп VII и VIII полициклических ароматических углеводородов, выделенных при повторном разделении в тонком слое окиси алюминия. (Обозначения пиков те же, что на рис. 2).

четкость разделения можно значительно повысить, проводя двукратное элюирование при составе растворителя, соответственно, $90: 10$ и $85: 15$. Распределение ПАУ по структурным группам дано на рис. 1. Расположение групп установлено по эталонным веществам; I и II группы содержат относительно полярные и высококипящие соединения, которые при ГЖХ пиков не образовывали. Количество этих прупп небольшое. Далее обсуждается состав групп, выделенных из слоя окиси алюминия.

В группе V основными компонентами являются ПАУ, содержащие три и более циклов, - здесь концентрируются флуорантен и пирен, но присутствуют также флуорен, фенантрен, антрацен и их алкилпроизводные. В группе VI концентрируются трициклические соединения - аценафтен, флуорен, фенантрен и антрацен, а также дифенил и его метилизомеры. Присутствуют также некоторые сернистые соединения, на хроматограммах отмеченные астериском. Группа VII содержит много нафталина и метилнафталинов, в ней концентрируются изомерные диметилнафталины, а также 2-этилнафталин. Группа VIII содержит алкилароматические соединения, продвинувшиеся дальше всех на пластинке. 

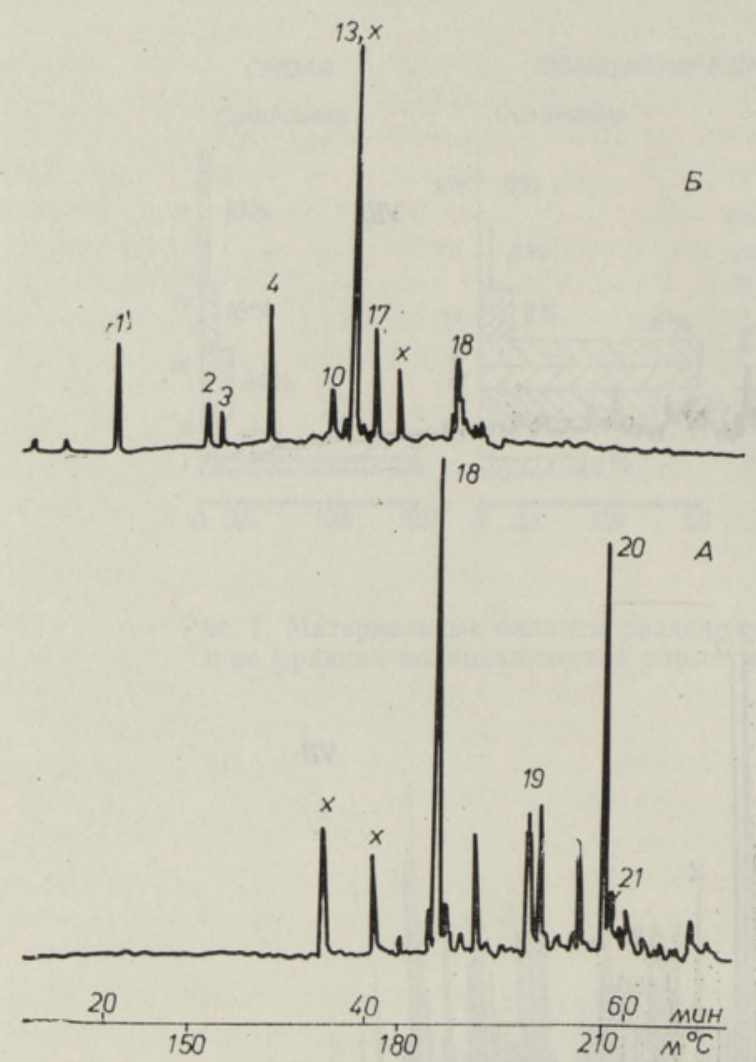

Рис. 4. Хроматограммы групп полициклических ароматических углеводородов третьего разделения в тонком слое окиси алюминия. $A$ - трициклические соединения, $E$ - производные нафталина и дифенила. (Обозначения пиков те же, что на рис. 2).

Хроматограммы VII и VIII групп существенно различаются (рис. 3). Алкилбензолы содержат соединения только с короткими боковыми цепями, присутствуют также индан и тетралин.

В целом, разделение ПАУ происходит на окиси алюминия лучше, чем на силикагеле, т. е. для более эффективного разделения при втором разделении лучше использовать другой адсорбент. Для исследования возможности дальнейшего фракционирования выделенных ароматических групп группа VI подвергалась дополнительному (третьему) разделению на слое окиси алюминия (пластинки $24 \times 12$ см, толщина слоя 1 мм, элюент - н-гексан-этиловый эфир 97,5:2,5, вещества 20 мг). Проба разделялась на две части, из которых сильнее адсорбируемая содержит, как основные компоненты, трициклические соединения флуорен и фенантрен, а слабее адсорбируемая - производные нафталина и дифенила (рис. 4). Разделение довольно четкое.

Опыты по разделению ароматических углеводородов показали, что способом препаративной ТСХ вполне возможно их разделение по количеству в них циклов. Это удается, если разделение проводится в 2-3 приема, где первое разделение - выделение самой группы полициклической ароматики.

На четкость разделения существенно влияет концентрация отдельных компонентов в пробе. Нафталин имелся в большом количестве, поэтому доходил до алкилбензольной фракции и в небольшом количестве оставался также во фракциях, где преобладают трициклические соединения. Если содержание веществ примерно одинаковое, разделение происходит полностью.

Препаративная ТСХ дает сведения о количестве отдельных структурных групп, распределении сложной смеси ПАУ по полициклическим системам. Одновременно облегчается идентификация газохроматографичеоких пиков, например, на исходной хроматограмме ароматических соединений (рис. 2, III) пики диметилнафталинов и метилдифенилов перекрываются, но после второго (рис. 3, VII) и третьего разделений (рис. 4,5 ) они находятся в отдельных группах. 
В анализируемой пробе отсутствовали частично гидрированные ПАУ, поэтому с повышением температуры кипения соединений и с увеличением их цикличности повышается также их полярность (высококипящие соединения адсорбируются сильнее). Можно предполагать, что при наличии гидрированных циклов комбинированный хроматографический метод даст больше результатов, чем было получено в настоящей работе.

\section{ЛИТЕРА Т У РА}

1. Klesment, I. Application of chromatographic methods in biogeochemical investigations. - J. Chromatogr., 1974, N 91, p. 705-713.

2. В ахесса а р В., Клесмент И., Э й зен О. Определение группового состава фенолов при помощи тонкослойной хроматографии. - Изв. АН ЭССР, Хим. Геол., 1968, т. 17 , № 1, с. 3-13.

3. Kichner, J. G., Miller, J. M. Preparation of terpeneless essential oils. Ind. Eng. Chem., 1952, v. 44, N 2, p. 318-321.

4. Arro, I. Ohukesekihilise kromatograafia ja paberikromatograafia kasutamisest polütsükliliste aromaatsete süsivesinike määramisel. - Изв. АН ЭССР, сер. физ. матем. и техн. н., 1964, т. 13 , № 1 , с. $47-51$.

5. Л ахе Л. А. Методика исследования и состав полициклических ароматических углеводородов сланцевых смол. Автореф. канд. дис. Таллин, 1972.

6. Перри С., Амос Р., Брюе р П. Практическое руководство по жидкостной хроматографин. М., 1974.

7. Hurtubise, R. J., Schabron, J. F., Feaster, J. D., Therkildsen, D. H. Fluorescence characterization and identification of polynuclear aromatic hydroearbons in shale oil. - Analyt. chim. acta, 1977, v. 89, N 2, p. $377-382$.

8. St a h l, E. Dünnschicht-Chromatographie. - Z. anal. Chem., 1961, Bd. 181, S. 303-312.

9. B a d ger, G. M., D on nelly, J. K., S potswood, T. M. Thin-layer chromatography using partially acetylated cellulose as adsorbent. - J. Chromatogr., 1963, v. $10, \mathrm{~N} 3$, p. $397-398$.

10. Pierce, R. C., Katz, M. Determination of atmospheric isomeric polycyclic arenes by thin-layer chromatography and fluorescence spectrophotometry. Anaiyt. Chem., 1975, v. 47, N 11, p. 1743-1748.

11. R a nd er at h, K. Dünnschicht-Chromatographie. Darmstadt, 1962.

12. Mostecký, J., Popl, M., K $\hat{r} i \hat{z}$, J. Determination of $\mathrm{C}_{12}$ alkylnaphthalenes and methylbiphenyls in aromatic fractions by capillary gas chromatography. Analyt. Chem., 1970, v. 42, N 11, p. 1132-1135.

13. Pichler, H., Ripperger, W., Schwarz, G. Kapillar-Gaschromatographie von Schwel-Hochtemperaturteeren. - Erdöl und Kohle, 1970, Bd. 23, H. 2, S. 91.

14. Lee, M. L., Hites, R. A. Characterization of sulfur-containing polycyclic aromatic compounds in carbon blacks. - Analyt. Chem., 1970, v. 48, N 13, p. $1890-1893$.

15. Severson, R. F., Snook, M. E., Arrendale, R. F., Chortyk, O. T. $\mathrm{Gas}$ chromatographic quantitation of polynuclear aromatic hydrocarbons in tobacco smoke, - Analyt. Chem., 1976, v. 48, N 13, 1866-1872.

16. L a o, R. C., Thom as, R. S., Monkma n, J. L. Computerized gas chromatographic-mass spectrometric analysis of polycyclic aromatic hydrocarbons in environmental samples. - J. Chromatogr., 1975, v. 112, p. 681-700.

17. Lao, R. C., Thomas, R. S., Oja, H., Dubois, L. Application of a gaschromatograph-mass spectrometer data processor combination to the analysis of the polycyclic aromatic hydrocarbon content of airborne pollutants. - Analyt. Chem., 1973, v. 45, N 6, p. $908-915$.

18. Borwitzky, H., Henneberg, G., Schomburg, G., S a uerland, H.-D., $\mathrm{Z}$ a nder, M. Steinkohlenhochtemperaturteer. - Erdöl und Kohle, 1977, Bd. 30 , H. 8 , S. 370 .

19. Grimmer, G., $B$ öhnke, H. Ein Anreicherungsverfahren für die gaschromatographische Bestimmung von PAH in Schmierölen. - Erdöl und Kohle, 1975, Bd. 28, H. 12 , S. 569 .

20. S a uerland, H. D., St adelhofer, J., Thoms, R., Z a nder, M. Neueres aus der Analytik der mehrkerniger Aromaten. - Erdöl und Kohle, 1977, Bd. 30 , H. 5, S. $215-218$. 
Saima SALUSTE, I. KLESMENT, Silvia KIVIRÄHK

\section{KEERUKA KOOSTISEGA AROMAATSETE SUSIVESINIKE KROMATOGRAAFILINE ANALUUS}

Artiklis on esitatud kombineeritud meetod õhukese kihi kromatograafiast ja gaasikromatograafiast. Preparatiivse ōhukese kihi kromatograafia abil on õlist eraldatud aromaatsed süsivesinikud, mis on polaarsema solvendi ja teistsuguse adsorbendi abil omakorda $1-2$ korda lahutatud rühmadeks tsüklite arvu ja teiste struktuurielementide alusel. Rühmi on analüüsitud kapillaarkromatograafiliselt mittepolaarsel faasil. On esitatud põlevkivi koksistamisel saadud õli analüüs.

Saima SALUSTE, I. KLESMENT, Silvia KIVIRAHK

\section{ANALYSIS OF AROMATIC HYDROCARBONS OF COMPLICATED COMPOSITION BY CHROMATOGRAPHIC METHODS}

Aromatic hydrocarbons are isolated from oil by preparative thin-layer chromatography and separated once or twice additionally using more polar solvent and another adsorbent, into groups in dependence on the number of cycles and other structural elements. Groups are analysed by capillar gas-chromatography on a nonpolar phase. An analysis of oil shale coking tar is presented. 